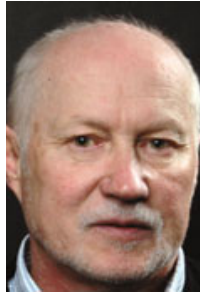

Bernd Kaina

1977 Promotion zum Dr. rer. nat. an der Universität Halle-Wittenberg. 1975-1984 wissenschaftlicher Mitarbeiter, Zentralinstitut für Genetik und Kulturpflanzenforschung, Gatersleben. 19841987 EU-Stipendiat am Institut für Biochemie, Universität Leiden, Niederlande, und Gastwissenschaftler am DKFZ, Heidelberg. 1987-1993 Arbeitsgruppenleiter am Institut für Genetik und Toxikologie, Kernforschungszentrum Karlsruhe. 1990 Habilitation an der Universität Karlsruhe. 1992 Venia Legendi für das Fach Genetik und Toxikologie an der Universität Karlsruhe. Seit 1993 Professor für Toxikologie an der Universität Mainz, seit 2004 Direktor des Instituts für Toxikologie.

DOI: $10.1007 / \mathrm{s} 12268-012-0211-\mathrm{y}$

(C) Springer-Verlag 2012

Es ist gut bekannt, dass während der Tumortherapie durch Bestrahlung oder Chemotherapeutika eine Schädigung des Immunsystems auftritt. Weniger bekannt ist, welche Zellen des Immunsystems besonders empfindlich auf Strahlung und Chemotherapeutika reagieren und welche resistent sind. Diese Frage wurde von unserer Arbeitsgruppe untersucht. Es zeigte sich, dass menschliche Monozyten besonders empfindlich auf reaktive Sauerstoffspezies (ROS) reagieren, während Makrophagen und dendritische Zellen (DCs), die aus Monozyten durch Zytokingabe gereift wurden, resistent sind [1]. Die

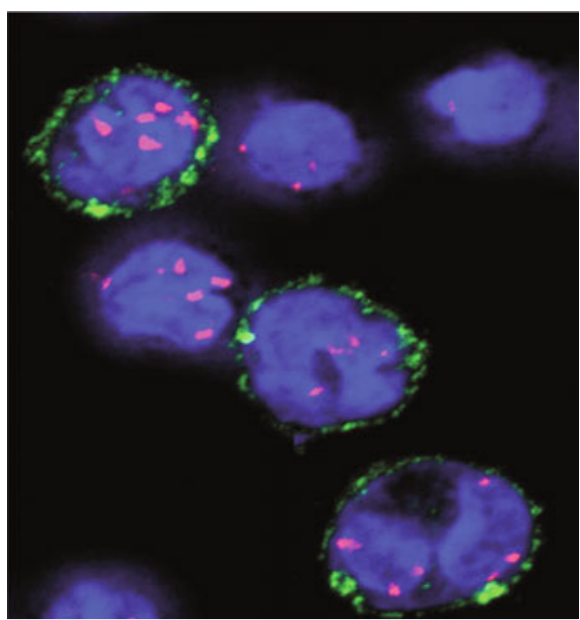

$\Delta$ Abb. 1: Menschliche Blutzellen bestrahlt mit 1-Gray-Gamma-Strahlung. Kernfoci (rot gefärbt), zeigen die Anwesenheit von DNADoppelstrangbrüchen an. Die Zellen wurden auch mit einem CD14-Antikörper gefärbt, ein Oberflächenmarker von Monozyten (grün). Die Kernfärbung erfolgte durch ToPro 3 (blau). Färbung und konfokale Mikroskopie durch Daniel Heylmann.

\section{GT-Toxicology-Preis 2012}

\section{Nachweis eines DNA-Reparaturdefekts in menschlichen Monozyten}

\author{
BERND KAINA \\ INSTITUT FÜR TOXIKOLOGIE, UNIVERSITÄT MAINZ
}

außerordentlich hohe Empfindlichkeit von Monozyten wurde nach Behandlung mit ionisierender Strahlung, chemischen oxidativen Substanzen und dem oxidierten low-densityLipoprotein (oxLDL), das als einer der Auslöser der Atherosklerose angesehen wird, beobachtet. Es gelang auch, die Ursache für die Hypersensitivität von Monozyten gegenüber oxidativem Stress ausfindig zu machen. Sie ist begründet in einem Fehlen bzw. einer äußerst niedrigen Expression der DNA-Reparaturproteine XRCC1, Ligase III, PARP-1 und DNA$\mathrm{PK}_{\mathrm{CS}}$. Damit sind Monozyten faktisch defekt in zwei wichtigen DNA-Reparatursystemen, der Basenexzisions-Reparatur (BER) und der DNA-Doppelstrangbruch(DSB)-Reparatur. Im letztgenannten Fall ist das nicht-homologe End-Joining (NHEJ) betroffen, das die DNAProteinkinase (DNA-PK) benötigt. Da die Zellen nicht proliferieren, stellt NHEJ den einzigen Weg der DSB-Reparatur in diesen Zellen dar, der offenbar nicht ablaufen kann und dazu führt, dass in Monozyten vermehrt DNADoppelstrangbrüche auftreten (Abb. 1). Das hat gravierende Auswirkungen auf die Sensitivität der Zellen, was an der starken Aktivierung der DNA-Schadensantwort und der hohen Apoptoserate nach ROS-Exposition zu sehen ist. Monozyten sind, verglichen mit DCs und Makrophagen, auch hypersensitiv gegenüber alkylierenden Genotoxinen, unter anderem auch Zytostatika [2]. Ein derartiger genereller Repararturdefekt wurde bisher weder in Zellen des menschlichen Körpers noch in experimentellen in vitro-Systemen beobachtet. Dem „Reparaturdefekt“ in Monozyten wird eine biologische Rolle zugeschrieben: die Vermeidung einer übermäßigen ROS-Produktion und Immunantwort durch Depletion des Präkursors von ROS-produzierenden Makrophagen und die Immunantwort regu- lierenden DCs (Monozyten) im entzündlichen Gewebe. Außerdem zeigen die Arbeiten, dass mehrere DNA-Reparaturgene durch Zytokine (GM-CSF und IL-4), die die Ausreifung von Monozyten zu DCs und Makrophagen bewirken, reguliert werden.

\section{Literatur}

[1] Bauer M, Goldstein M, Christmann M et al. (2011) Human monocytes are severely impaired in base and DNA doublestrand break repair that renders them vulnerable to oxidative stress. Proc Natl Acad Sci USA 108:21105-21110

[2] Bauer M, Goldstein M, Heylmann D et al. (2012) Human monocytes undergo excessive apoptosis following temozolom de activating the ATM/ATR pathway while dendritic cells and macrophages are resistant. PLOS ONE (im Druck).
Korrespondenzadresse: Prof. Dr. Bernd Kaina Universität Mainz Institut für Toxikologie Obere Zahlbacher Straße 67 D-55131 Mainz

Tel.: 06131-17-9217

Fax: 06131-230506

kaina@uni-mainz.de 